\title{
Asthma and its Associated Triggering Factors among Medical Students at Ha'il University
}

\author{
Mohamed Ahmed Babikir Bealy ${ }^{1 *}$, Abdullaziz Mohammed Alshammari ${ }^{2}$, Sultan Saud Abdulaziz Altamimi ${ }^{1}$, \\ Abdulrahman RabahTabiAlsharari ${ }^{2}$, Hassan Salamah Alfehaid, Emad Abboh ${ }^{1}$ \\ ${ }^{1}$ Assistant Professor, Department of Pathology, College of Medicine, University of Ha'il, Saudi Arabia \\ ${ }^{2}$ Medical Student Five year, College of Medicine, University of Ha'il, Saudi Arabia
}

\author{
DOI: $10.36348 /$ sjpm.2020.v05i12.003 $\quad$ | Received: 21.11 .2020 | Accepted: 03.12 .2020 | Published: 10.12 .2020 \\ *Corresponding author: Mohamed Ahmed Babikir Bealy
}

Abstract

Background: Asthma still the mainly prevalence chronic respiratory disease affecting individuals in different ages. The objective of this study was to find out the prevalence of asthma, and its triggering factors among medical students in the College of Medicine University of Hai'l city, Saudi Arabia. Methodology: The study investigated 198 students using online questionnaire. Results: The 198 male medical studentsaged between $20-27$ years with mean age of 21.5. The overall prevalence of asthma in in the medical students at the College of Medicine University of Hai'l was $10 \%$.Regarding to things that aggravates asthma symptomsdust 5/20(25\%), smoke $2 / 20(10 \%)$, dust+smoke $4 / 20(20 \%)$, dust+stress $1 / 20(5 \%)$, dust+smoke+stress+animals $2 / 20(10 \%)$, dust+smoke+cold weather $3 / 2(15 \%)$, dust+animal+stress $1 / 20(5 \%)$ and dust+coldweather+animals $2 / 20(10 \%)$. Conclusion: The prevalence of asthma in medical students is relatively high compared to global prevalence rates. The most common allergies triggering asthma symptoms in the college of Medicine, university of Hail, are dust, smoking, Animals and stress.

Keywords: Asthma, dust, smoking, Saudi Arabia, medical students.

Copyright (C) 2020 The Author(s): This is an open-access article distributed under the terms of the Creative Commons Attribution 4.0 International License (CC BY-NC 4.0) which permits unrestricted use, distribution, and reproduction in any medium for non-commercial use provided the original author and source are credited.

\section{INTRODUCTION}

Asthma is clinical conditions which can found in different ages. Occurrence has been rise in last decades all over the world. New information has told that the occurrence of asthma has changed and show declining in some countries although it still increase in others place of the earth [1].

Worldwide asthma is $16^{\text {th }}$ of most important of annually cause of morbidity and $28^{\text {th }}$ of majored lead to trouble of illness. Nearly 300 million of individuals have asthma globally, it suspected that by year 2025 additional hundred million possibly affect [2].

Up to now no clear etiology known for asthma this indicate the complexity of this disorder, in children asthma is related closely to mal lung function for first three to four years, hence the alveolization yet not complete. In adult the role of fungal infection as primary to allergic disorder is well confirm, although it's unclear that early exposure in infant or post-natal lung maturation is with protective effect or enhancing asthma. Immune response of individual play a basic role in early progressing asthma [3]. Symptoms of asthma always appear as reversible airway obstruction that presents with association of wheezing, dyspnea, hyperresponsivenes, cough and increase mucus secretion [4].

Diagnosis of asthma is controversially thus no single environmental or genetic factor known to be as chief causative. Exact diagnosis of asthma constituent needs intent measurements.Now a day Spirometry and airway responsiveness should be on hand for all health common practitioners, who deal with cold cases and moreover counting of sputum cells in specialist sector, in which moderate to aggressive illness is more common [5].

Pathophysiology of asthma is highly complicated, although family history is play an important role, nevertheless the genes governed inheriting asthma still undetermined. The mechanism of phenotype of asthma that it has a well fixed relation to be hereditary, still the mechanism is more unclear, as it's not fit with Mendelian model. Most probably asthma is inherited by many genes, with different in locus heterogeneity and variation of gens let asthma appearance to be comprehensive.Immunoglobulins E 
attack specific antigens, which can contribute to the disease. Many studiesreveal that asthma has strong relation to total immunoglobulin $\mathrm{E}$ ( $\mathrm{IgE}$ ) level in serum [6]. IgEresponse stimulate due to various environmental stimuli i.e. house dust, animals, mold, stress and farm animals, all can share or individually to sensitize asthma and aggravates it's symptoms, then lead to airway reactivity due to high contact to irritants. Up to now no enough data available on behalf of asthma pathophysiolog [7]. The most things that induce asthma were dust, smoke, recurrent respiratory infections and changing in climate manyothers such as animals, stress and vigour exercise with minimum role [8].

Management and control of asthma is depend on many potential actions, patients education on behalf of treatments an preventive medications is effective method to decrease burden harmful breathing problems and others symptoms [9], SABA drugs is one of the major treatment used with asthmatics patient however studies show that anti inflammatory drug enhance is sportive required with SABA and LABA [10].

Although asthma is one of most prevalence non-commutable disease but still no longer enough data available from Hai'l region especially in adult, thus the present study aimed to given data that help in improved strategies and control to reduce asthma trouble in Hai'l KSA.

\section{METHODOLOGY}

This is cross sectional study aimed to determine the prevalence of asthma in University of Ha'il College of Medicine. Online questionnaire was designeddistributedfor diverse social groups. The deception and purpose of study were revealed at start of online questionnaire. Moreover, it was explain for participant that by finishing and sending the questionnaire that indicate agreed to be include in this study and the final finding will be committed for scientific use.

\section{Design of questionnaire}

The questionnaire included age, questions about is the participant asthmatic or not, for asthmatics participants; when first time diagnosed with asthma with options of early childhood, late childhood, early adult and late adult, and also question do asthmatics participant use medication for his asthma with yes or not, and what the types of drug you use with choice of not use, use LABA, use SABA and others. The frequent symptoms occur when asthma attack start i.e. (cough, wheeze, chest tightness or breathlessness) with options of all symptoms, some of them, no symptoms. Question about do you think your asthma is mild, moderate or severe. Does asthma affect your daily activities? Options was yes or No. Participants also asked about either they smoker or no, question about things that aggravates their asthma was razed such as smoke, dust, stress, cold weather and animals. Last question related to hospitalize due to asthma with yes or no choices.

\section{Statistical Analysis}

Data analysis was performed using SPSS. Descriptive statistic was done and frequencies and crosstabs had performed for every variable.

\section{Ethical Approval}

The study ethical approval was get from ethical committee of the College of Medicine University of Hail. Approval Number: HREC.

\section{RESULTS}

The current study included 198 medical students' volunteers, their ages ranging from There 20 27 years with a mean age of 21.5 years, as shown in Table-1. Out of 198 study subjects, 20 (10\%) were asthmatic, while the remaining $178(90 \%)$ were notas shown in Fig 1.With regard to the age of diagnosis,9/198(4.5\%) were initially diagnosed atchildhood, $8 / 198(4 \%)$ in late childhood, $2(1 \%)$ in early adulthood and only one $(0.5 \%)$ in late adult, as shown in Fig-2. Regardingmedicationsuse, 11(5.6\%) were not use any drug, while $9(9.2 \%)$ were medication dependent. Regarding treatment type, they have used either SABA $9(4.5 \%)$ or LABA $9(4.5 \%)$ and $2(1 \%)$ was not use any drugs see Fig 3 and 4. Concerning Cough, wheeze, chest tightness and breathlessness were the most frequent asthma symptoms reported by the majority of patients. About 4/20(20\%), 15/20(75\%), and $1 / 20(5 \%)$ have reported all symptoms, some symptoms, and none, respectively. For asthma severity, $14(7 \%)$ were with mild when $5(2.5 \%), 1(0.5 \%)$ with moderate and severe attack respectively, as shown in Fig 5 and 6. For those asthmatic participants daily activities were affected in $5 / 20(25 \%)$ and not affected in the remaining 15/20(75\%), as shown in Fig-7. From asthmatics responder $18 / 20(90 \%)$ of them were nonsmokers while $2(10 \%)$ were smokers as shown in Fig-8. Regarding to things that aggravates asthma symptomsdust $5 / 20(25 \%)$, smoke $2 / 20(10 \%)$, dust+smoke 4/20(20\%), dust+stress 1/20(5\%), dust+smoke+stress+animals $2 / 20(10 \%)$, dust+smoke+cold weather 3/2(15\%), dust+animal+stress $1 / 20(5 \%)$ and dust+coldweather+animals $2 / 20(10 \%)$ as shown in Table-2. 10/20(50\%) of participant with asthma were never been hospitalize when remaining $10(50 \%)$ were hospitalize as minimum one time a life see Fig- 9 .

Table-1: Shows distribution of study population with asthma by age

\begin{tabular}{|l|l|l|l|}
\hline Age & Non asthmatic & Asthmatic & Total \\
\hline 20 & 55 & 8 & 63 \\
\hline 21 & 62 & 3 & 65 \\
\hline 22 & 9 & 0 & 9 \\
\hline 23 & 19 & 7 & 26 \\
\hline 24 & 32 & 2 & 34 \\
\hline 27 & 1 & 0 & 1 \\
\hline Total & 178 & 20 & 198 \\
\hline
\end{tabular}


Table-2: Distribution of participant by factors that aggravate asthma

\begin{tabular}{|l|l|l|}
\hline Things aggravate asthma & Asthmatics & Non asthmatic \\
\hline Smoke & 2 & 0 \\
\hline Dust & 5 & 0 \\
\hline Dust+ smoke & 4 & 0 \\
\hline Dust+ stress & 1 & 0 \\
\hline Dust+ smoke+ stress+ animals & 2 & 0 \\
\hline Dust, smoke; cold weather & 3 & 0 \\
\hline Dust, animal; stress & 1 & 0 \\
\hline Dust, cold weather; animals & 2 & 0 \\
\hline Total & 20 & 178 \\
\hline
\end{tabular}

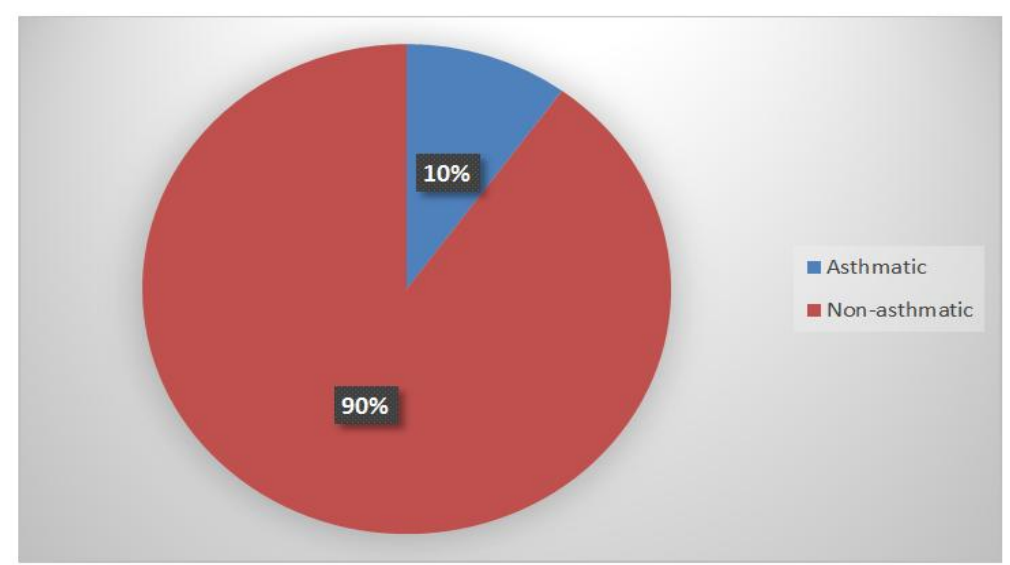

Fig-1: Description of the participants by asthma status

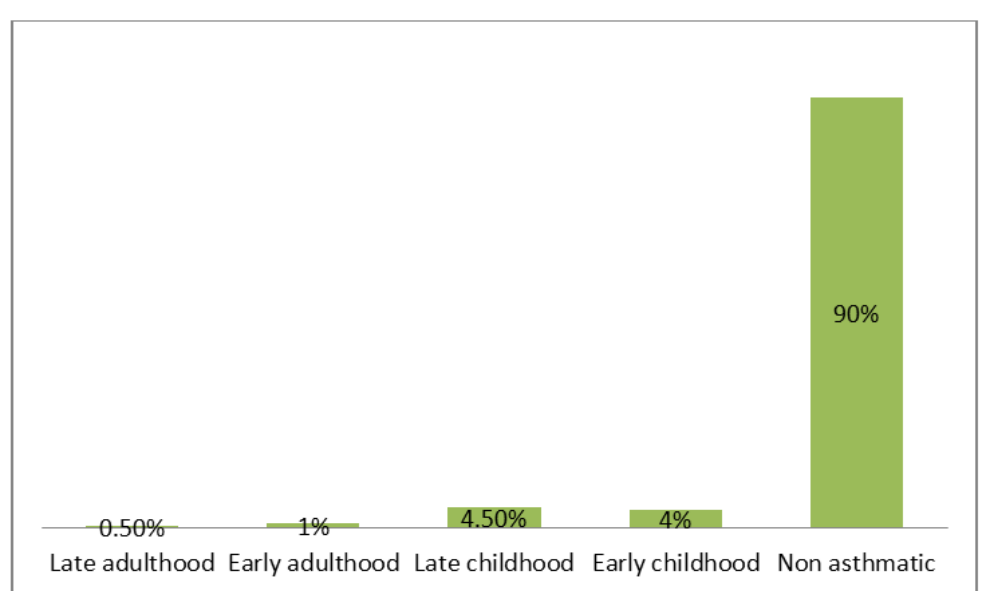

Fig-2: Description of the participantsby age at diagnosis

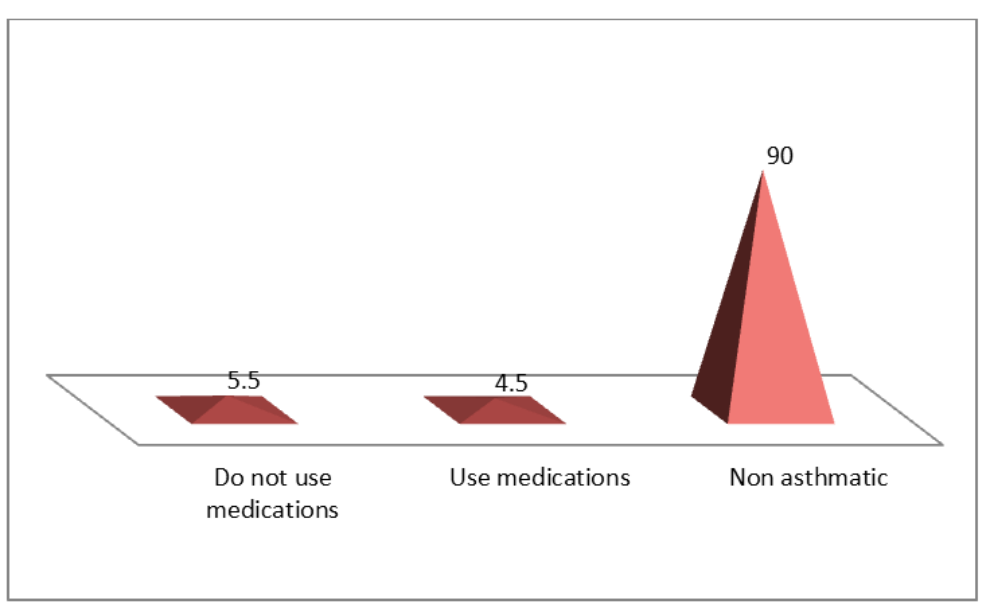

Fig-3: Description of the participants by medication 


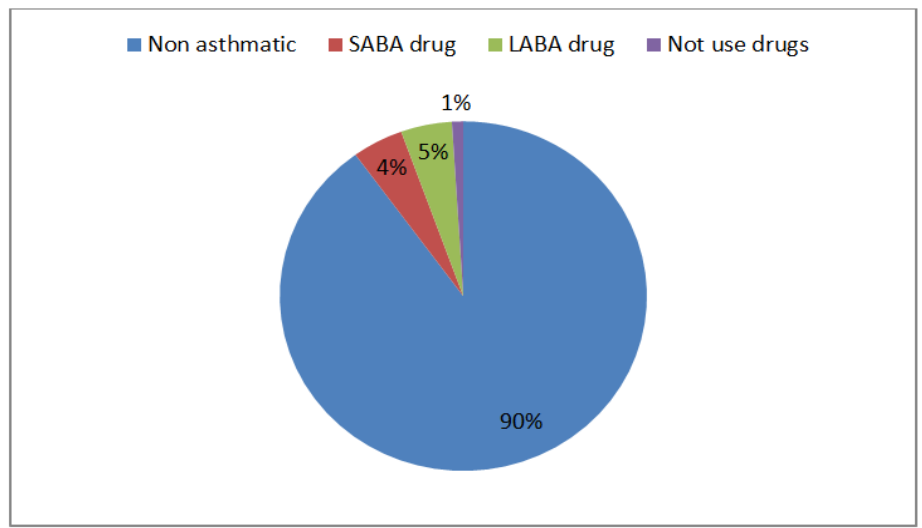

Fig-4: Description of participant bydrug type

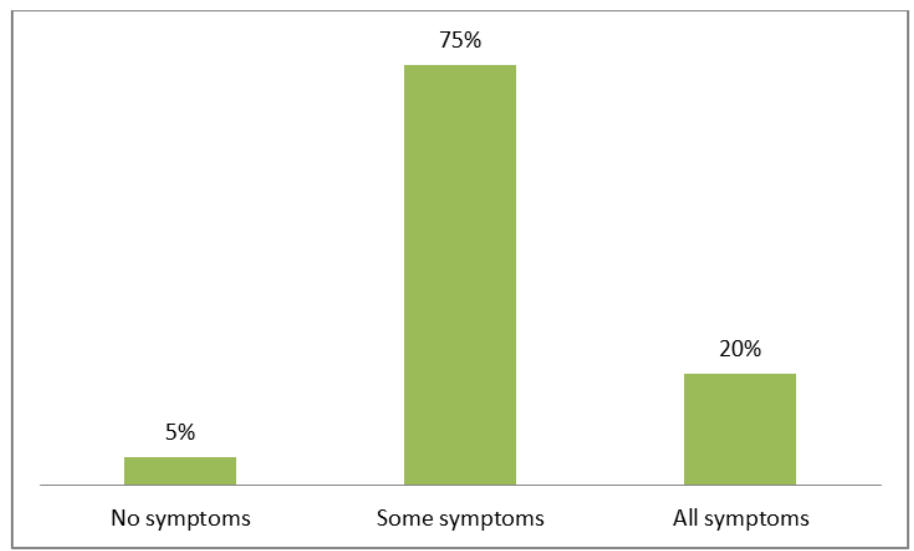

Fig-5: Description of participantsby symptoms (cough, wheeze, chest tightness or breathlessness)

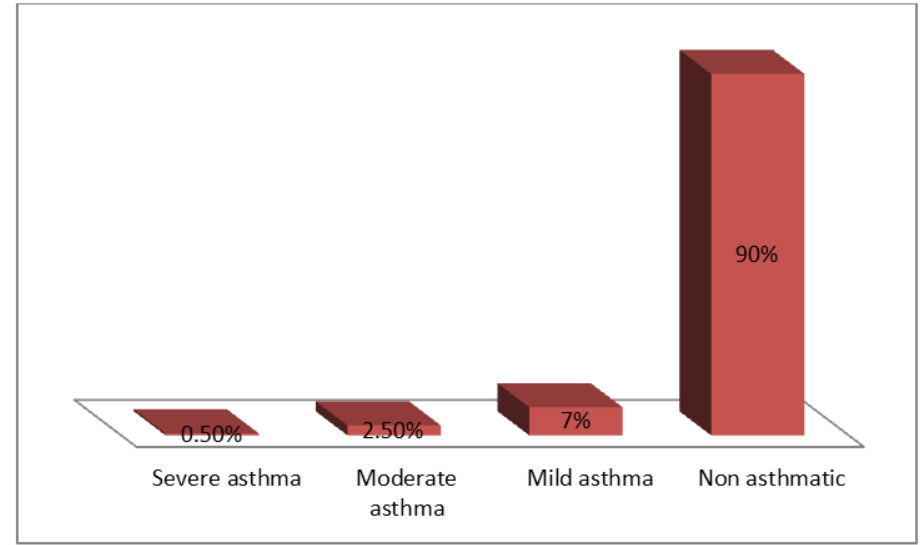

Fig-6: Description of participants by severity

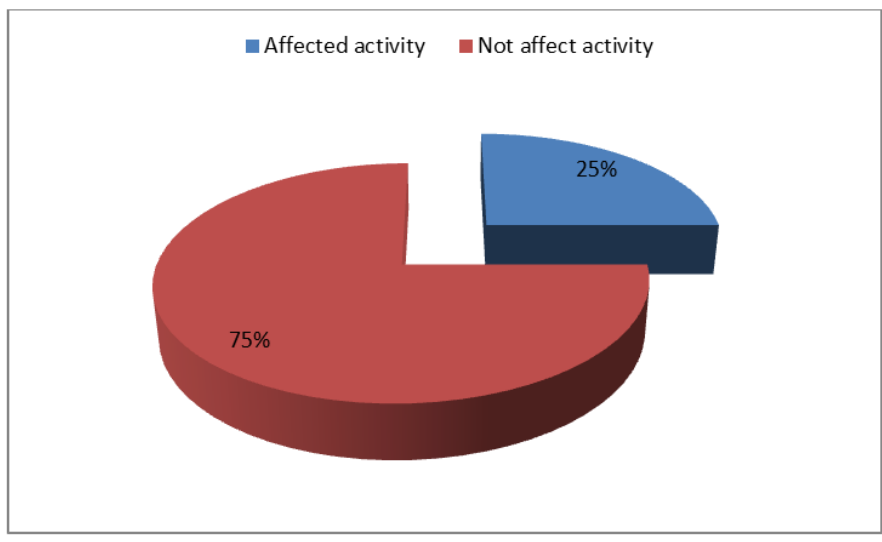

Fig-7: Description of asthmatics participant by activity affecting 


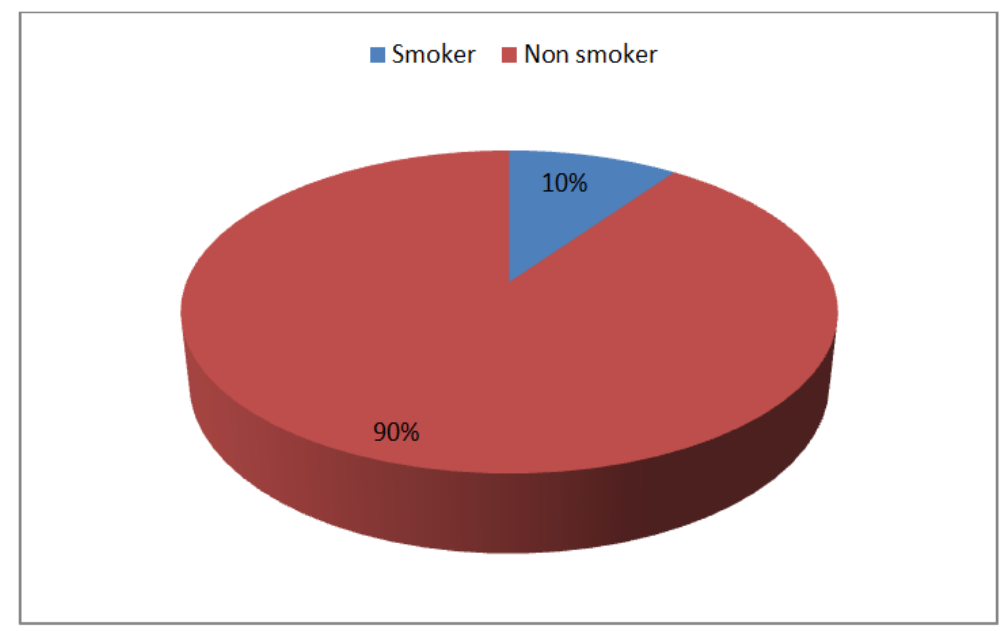

Fig-8: Description of asthmatics participant bysmoking

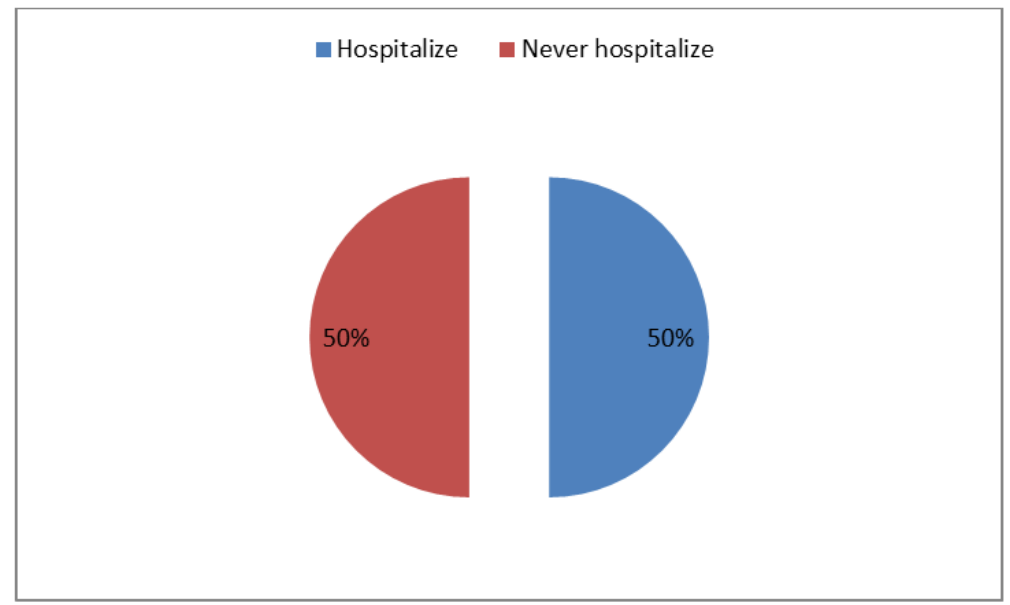

Fig-9: Description of asthmatics participant by hospitalization

\section{DISCUSSION}

Asthma is the most common respiratory disease and offended about one third worldwide, about 2.5 million deaths annually due to severe exacerbation [11]. In the current study the prevalence of asthma among male students in college of medicine university of Hai'l was $10 \%$, which relatively lower than global and Middle East prevalence rates. However, the findings of the present study is close to reported prevalence rates in Saudi Arabia (11.2\%) [12]. Worldwide, prevalence of asthma was 3.6\% [13], while in study conducted in Khuzestan revealed that the prevalence was $8.5 \%$ [14]. Such diversity indicates the influence of environmental and geographical factors in the etiology of asthma.

In present study the participants' age was between $20-27$ years, and the most affected were those aged 20 years representing $40 \%$. Although one study shows that, the incidence of asthma increases after middle age 18 years and reaches its peak in the age of 40 years [15].

The prevalence of asthma was varying between males and females in adolescence, and it was significant for female's gender [16].In existing study only male students were include. In study conducted in Saudi Arabia Riyadhreporteda prevalence of $18.2 \%$ for asthma without significant different between males and females $(p=0.107)$ [17].

In the current study, wheeze, cough, and breathlessness were identified in $75 \%$ of asthmatic participants, which agreed with Saudi Arabia high prevalence of asthma associated symptoms about $61 \%$, it is close to the global prevalence range [18].

The chief factors aggravate asthma founded in this investigation was dust $25 \%$, and smoke $10 \%$, and it may associate with other triggering factors such as animals, stress and vigor exercise, these findings agreed with study conducted in Singapore Chinese health study in which dust had significant association with asthma symptoms (odd ratio $(\mathrm{OR})=1.19 ; 95 \%$ confidence interval (CI): 1.8, 1.30) [19]. In study for risk of asthma with passive smoke, the results was revealeda significant association (odd ratio (OR), 1.90;95\% confidence interval (CI), 1.16 to 3.11 ) [20]. For Saudi populations in a study conducted in Al-Taif city they found that symptoms of upper respiratory tract were 
significantly more prevalence in people who expose to dust $(\mathrm{P}=0.004)[21]$.

The limitation of the current study included its online questionnaire data collection and small sample size.

\section{CONCLUSION}

The prevalence of asthma in medical students is relatively high compared to global prevalence rates. The most common allergies triggering asthma symptoms in the college of Medicine, university of Hail, are dust, smoking animals and stress.

\section{REFERENCES}

1. Stern, J., Pier, J., \& Litonjua, A. A. (2020, February). Asthma epidemiology and risk factors. In Seminars in Immunopathology (pp. 1-11). Springer Berlin Heidelberg.

2. Dharmage, S. C., Perret, J., \& Custovic, A. (2019). Epidemiology of asthma in children and adults. Frontiers in pediatrics, 7, 246.

3. Hadebe, S., \& Brombacher, F. (2019). Environment and host-genetic determinants in early development of allergic asthma: Contribution of fungi. Frontiers in Immunology, 10, 2696.

4. Patadia, M. O., Murrill, L. L., \& Corey, J. (2013). Asthma: symptoms and presentation. Otolaryngologic Clinics of North America, 47(1), 23-32.

5. Liu, D., Tan, Y., Bajinka, O., Wang, L., \& Tang, Z. (2020). Th17/IL-17 Axis Regulated by Airway Microbes Get Involved in the Development of Asthma. Current Allergy and Asthma Reports, 20(4), 1-9.

6. Sinyor, B., \& Concepcion, P. L. (2020). Pathophysiology of Asthma. 2020 Jul 10. In: StatPearls [Internet]. Treasure Island (FL): StatPearls Publishing; 2020 Jan.

7. Pelaia, C., Paoletti, G., Puggioni, F., Racca, F., Pelaia, G., Canonica, G. W., \& Heffler, E. (2019). Interleukin-5 in the pathophysiology of severe asthma. Frontiers in Physiology, 10, 1514.

8. Saka, V. N. (2019). A Critical Review: Tamaka Shwasa (Bronchial Asthma). International Journal of Research-GRANTHAALAYAH, 7(8), 258264.

9. Polk, B. I., \& Dinakar, C. (2019). Management of acute loss of asthma control: yellow zone strategies. Current opinion in allergy and clinical immunology, 19(2), 154-160.

10. Muneswarao, J., Hassali, M. A., Ibrahim, B., Saini, B., Ali, I. A. H., \& Verma, A. K. (2019). It is time to change the way we manage mild asthma: an update in GINA 2019. Respiratory research, 20(1), 183.

11. Rehman, A., Amin, F., \& Sadeeqa, S. (2018). Prevalence of asthma and its management: A review. JPMA. The Journal of the Pakistan Medical Association, 68(12), 1823-1827.

12. Honkamäki, J., Hisinger-Mölkänen, H., Ilmarinen, P., Piirilä, P., Tuomisto, L. E., Andersén, H., ... \& Rönmark, E. (2019). Age-and gender-specific incidence of new asthma diagnosis from childhood to late adulthood. Respiratory medicine, 154, 56-62.

13. Lopes, G. P., Amorim, Í. P. S., Melo, B. D. O. D., Maramaldo, C. E. C., Bomfim, M. R. Q., Lima Neto, L. G., ... \& Falcai, A. (2020). Identification and seasonality of rhinovirus and respiratory syncytial virus in asthmatic children in tropical climate. Bioscience reports, 40(9).

14. Fanny W.S. Ko, David S.C. Hui, Asthma-COPD overlap: No formal definition and simple diagnostic tool so far?, Respirology,2019: 25(7) 672-673.

15. Pakkasela, J., Ilmarinen, P., Honkamäki, J., Tuomisto, L. E., Andersén, H., Piirilä, P., ... \& Rönmark, E. (2020). Age-specific incidence of allergic and non-allergic asthma. BMC pulmonary medicine, 20(1), 1-9.

16. Kalm-Stephens, P., Nordvall, L., Engvall, G., Janson, C., Malinovschi, A., \& Alving, K. (2020). Incidence of asthma between adolescence and adulthood: early risk factors and gender differences.

17. Al Ghobain, M. O., Algazlan, S. S., \& Oreibi, T. M. (2018). Asthma prevalence among adults in Saudi Arabia. Saudi medical journal, 39(2), 179184.

18. Al Ghobain, M. O., Al-Hajjaj, M. S., \& Al Moamary, M. S. (2012). Asthma prevalence among 16-to 18-year-old adolescents in Saudi Arabia using the ISAAC questionnaire. BMC Public Health, 12(1), 239.

19. LeVan, T. D., Koh, W. P., Lee, H. P., Koh, D., Yu, M. C., \& London, S. J. (2006). Vapor, dust, and smoke exposure in relation to adult-onset asthma and chronic respiratory symptoms: the Singapore Chinese Health Study. American journal of epidemiology, 163(12), 1118-1128.

20. Radon, K., Bu, K., Heinrich, J., Wichmann, H. E., Jo, R. A., Magnussen, H., \& Nowak, D. (2002). Passive smoking exposure: a risk factor for chronic bronchitis and asthma in adults?. Chest, 122(3), 1086-1090.

21. El Margoushy, N., Al Hussini, H. A., Abdullah, K., \& Almuntashiri, A. S. A. A. (2019). Role of medical surveillance in detecting Baker's asthma in Taif city, Saudi Arabia. International Journal of Medicine in Developing Countries, 3(1):10-14. 